\title{
Evolution of International Peace and Conflict Resolution Studies
}

\author{
Omar Habibal \\ Sultan Qaboos University, Oman \\ Omar_hadid.stu@squ.om
}

\begin{abstract}
In this paper review of the International Peace literature, specifically exploring the contemporary trends that function to align International Peace theory and practice with dominant interests. I begin with a critical historical overview of the development of this field, looking at the primary influences that have shaped and continue to impact it. A variation on this, peace studies (irenology), is an interdisciplinary effort aiming at the prevention, de-escalation, and solution of conflicts by peaceful means, thereby seeking "victory" for all parties involved in the conflict. This is in contrast to military studies, which has as its aim on the efficient attainment of victory in conflicts, primarily by violent means to the satisfaction of one or more, but not all, parties involved. Disciplines involved may include philosophy, political science, geography, economics, psychology, sociology, international relations, history, anthropology, religious studies, and gender studies, as well as a variety of others. Relevant sub-disciplines of such fields, such as peace economics, may be regarded as belonging to peace and conflict studies also.
\end{abstract}

This establishes a power disparity between the conflict actors and the conflict resolution theorists/ practitioners, exacerbating the distance between the two groups and privileging the latter.

Keyword: International Peace; Conflict Resolution; Violent and Nonviolent Behaviors

\section{Introduction}

The origins of conflict resolution often are traced back to the labor-management bargaining and organizational development initiatives. In the early part of the 20th century, management theorists such as Frederick Taylor were interested in removing inefficiency in the workplace caused by conflict between employers and employees.

The Conflict and Resolution Studies concentration provides interdisciplinary and international perspectives on the causes of conflict and the possibilities of resolution. The concentration offers theoretical insights into the causes of conflict-some positive and creative but far too many tragically destructive. The concentration courses embrace the study of interpersonal, intergroup, and societal conflicts in different cultures across the world. Exploration of resolution strategies, social justice issues, ethical concerns, and leadership qualities are features of the concentration. 
The negative and positive peace framework is the most widely used today. Negative peace refers to the absence of direct violence. Positive peace refers to the absence of indirect and structural violence, and is the concept that most peace and conflict researchers adopt. This is often credited to Galtung, but these terms were previously used by Martin Luther King in the Letter from a Birmingham Jail in 1953, in which he wrote about "negative peace which is the absence of tension" and "positive peace which is the presence of justice." These terms were perhaps first used by Jane Addams in 1907 in her book Newer Ideals of Peace (Gurr, 1993).

Internationally, violence resulted in the deaths of an estimated 1.28 million people in 2013 up from 1.13 million in 1990 . Of the deaths in 2013, roughly 842,000 were attributed to self-harm (suicide), 405,000 to interpersonal violence, and 31,000 to collective violence (war) and legal intervention. In Africa, out of every 100,000 people, each year an estimated 60.9 die a violent death. For each single death due to violence, there are dozens of hospitalizations, hundreds of emergency department visits, and thousands of doctors' appointments. Furthermore, violence often has lifelong consequences for physical and mental health and social functioning and can slow economic and social development.

In 2013, assault by firearm was the leading cause of death due to interpersonal violence, with 180,000 such deaths estimated to have occurred. The same year, assault by sharp object resulted in roughly 114,000 deaths, with a remaining 110,000 deaths from personal violence being attributed to other causes.

Violence in many forms can be preventable. There is a strong relationship between levels of violence and modifiable factors in a country such as a concentrated (regional) poverty, income and gender inequality, the harmful use of alcohol, and the absence of safe, stable, and nurturing relationships between children and parents. Strategies addressing the underlying causes of violence can be relatively effective in preventing violence, although mental and physical health and individual responses, personalities, etc. have always been decisive factors in the formation of these behaviors.

Several conceptions, models, or modes of peace have been suggested in which peace research might prosper. The crux of the matter is that peace is a natural social condition, whereas war is not. The premise is simple for peace researchers: to present enough information so that a rational group of decision makers will seek to avoid war and conflict (Kemp, 2000).

Second, the view that violence is sinful or unskillful, and that non-violence is skillful or virtuous and should be cultivated. This view is held by a variety of religious traditions worldwide: Quakers, Mennonites and other Peace churches within Christianity; Bahais, Jains, the Satyagraha tradition in Hinduism, Buddhism, and other portions of Indian religion and philosophy; as well as certain schools of Islam.

Third is pacifism: the view that peace is a prime force in human behavior $\mathrm{r}(\mathrm{Kemp}, 2000)$.

There have been many offerings on these various forms of peace. These range from the well-known works of Kant, Locke, Rousseau, Paine, on various liberal international and constitutional and plans for peace. Variations and additions have been developed more recently by scholars such as Raymond Aron, Edward Azar, John Burton, Martin Ceadal, Wolfgang Dietrich, Kevin Dooley, Johan Galtung, Michael Howard, Vivienne Jabri, John-Paul Lederach, Roger Mac Ginty, Pamina Firchow, Hugh Miall, David Mitrany, Oliver Ramsbotham, Anatol Rapoport, Mikkel Vedby Rasmussen, Oliver Richmond, S.P. Udayakumar, Tom Woodhouse, others mentioned above and many more. Democratic peace, liberal peace, sustainable peace, civil peace, hybrid peace, post-liberal peace, everyday peace, trans-rational peace(s)and other concepts are regularly used in such work (Jones, 1999). 
Under the conceptions of peace, sustainable peace must be regarded as an important factor for the future of prosperity. Sustainable peace must be the priority of global society where state actors and nonstate actors do not only seek for the profits in a near future that might violate the stable state of peace. For a sustainable peace, nurturing, empowerment, and communications are considered to be the crucial factors throughout the world. Firstly, nurturing is necessary to encourage psychological stability and emotional maturity. The significance of social value in adequate nurturing is important for sustainable peace. Secondly, in order to achieve real security, inner security must be secured along with arranged social systems and protection based on firm foundation. Lastly, communications are necessary to overcome ignorance and establish a community based on reliable and useful information. It will prevent isolation to take place which is critical to bring sustainable peace (Kelman, 2005).

Alan Tidwell discusses the further development of organizational and management approaches to conflict resolution, the rise of such techniques as mediation, arbitration, and facilitation, and their significance to the field:

The strength of organizational development approaches, as Tidwell concludes, has been in applying conflict resolution strategies to real-life situations $(1998,12)$.

Importantly, however, Richard Rubenstein argues that the development of this type of conflict resolution theory/practice was not designed to address economic class conflict. As such, its primary effect was to incorporate interest groups into the capitalist free market system and maintain the current system of power inequality. He asserts that this is a 'conflict management' technique, which "relies on power-based instrumentalities, e.g. legal systems that seldom address the causes of conflict at their systemic level" (1993, 146).

\section{Discussion}

In the 1960s, there was a growing body of religious and peace activism. The Quakers and the Mennonites, with their long-standing commitment to pacifism, helped to develop alternatives to violent conflict. They have been very influential in the peace activist circles and also have influenced theoretical approaches (Lederach 2000). Their main contribution has been an unrelenting opposition to state sponsored violence and war. Further, their activism contributed significantly, as they applied their beliefs to real life situations and, at times, put their lives on the line for their vision of justice. Quaker and Mennonite opposition to the Vietnam War and other state sponsored atrocities-in conjunction with other pacifist activists like Martin Luther King Jr. (particularly 1965-68 \}-was part of a significant challenge to the way in which U.S. foreign and domestic policy was viewed. They helped to pose alternatives to the traditional International Relations paradigm of 'realist' power politics. They posed a critical challenge to the Machiavellian understanding of violence and war and helped to promote the strong orientation towards nonviolence that has become a central component of the IPCR field. At the same time, however, both in the 1960s and after, rigidly nonviolent peace activists, such as Colman McCarthy, have used 'pacifism' to denounce and exclude low power groups that chose to take a more militant or confrontational approach to challenging power inequality and injustice (Hunt, 1980).

The challenge that pacifists have posed to the traditional realist power politics of International Relations has been significant. However, the paradigm shifts away from 'power' also has spawned approaches that have worked against low power actors, not just against the state. Some of these new analyses and approaches for dealing with international conflict have become particularly problematic in this regard. 
This approach was later accompanied by trends in conflict analysis towards the ethnicization or religiocization of conflicts that are rooted in colonialism and imperialism. Bill Rolston explains that this process has resulted in a downplaying of colonial and imperialist power dynamics in certain conflict situations. It has given way to a reframing of colonial conflicts as merely 'ethnic' or 'religious.'

The conflicts in Palestine/Israel and the North of Ireland are prime examples of cases that are commonly portrayed as conflicts between two religious or ethnic groups when, in fact, they are both deeply rooted in colonialism (Rowe, 2011).

The dominant paradigm of religious or ethnic conflict tends to negate the effects of imperialism/colonialism and, at worst, tends to eliminate analysis of power disparity altogether. Portraying the conflict in Ireland as Catholics versus Protestants removes Britain as a major antagonist (a colonial occupying force) in the current conflict. This is similar to the way that much of the mainstream analysis of the Israeli-Palestinian conflict-framed in either religious or ethnic tens-has removed the United States as a major antagonist, while the U.S. government continue to fund Israel as a client regime with approximately three billion dollars a year in direct aid (Lasensky, 2004).

The San Fransisco Community Boards (founded in 1976) on the other hand were not directly linked to the courts. They were intended to provide citizens with alternative models to resolving neighborhood disputes (Tidwell 1998, 14).

The trends outlined thus far clearly have affected the paradigms and approaches in the contemporary IPCR field/community in both positive and negative ways. While there have been extensive writings documenting the positive contributions, such as the move away from the realist power-politics of international relations, I am concerned with how this field's development also has been a deradicalizing or status-quo-oriented move away from community-based activist organizing, radical politics, and grassroots resistance struggles.

Game theory is a systematic and mathematical study of problem solving. Mathematicians and economists have advanced this approach in an attempt to study human problem solving behavior. It was promoted also because it suggests that conflicts do not necessarily have to be zero-sum games in which victory for one party means defeat of the other. For this reason, game theory was popular during the Cold War when policies of nuclear deterrence were influencing the major powers (Mock, Obeidi, \& Zeleznikow, 2012).

Two people are arrested for a crime and are separated for interrogation. Neither robber knows what the other will say, though they do have perfect knowledge of the range of possible outcomes. If both squeal, they both get a light sentence of 5 years. If neither squeals, they both go to jail for life. The difficulty is that, if one tells all and the other one says nothing, the squealer goes to jail for life and the other goes free. The prisoners have no way of communicating or telling what the other will do. Hence, they are in a dilemma.

This game is characterized by mistrust. The primary point of the exercise is for parties to develop strategies for the lack of certainty about what the other party will do. But this could have the effect of locking the parties into escalating conflict when none was necessary.

Game theory has introduced terminology like 'win-win' to describe the outcomes of a conflict situation such as the Prisoner's Dilemma, which is mutually beneficial (though not perfect) for both parties.

These approaches promote generic models that should be applicable to all conflicts. They declare their book, Beyond Machiavelli, to be "a tool box for the problem solver" \{1994, 17). The main point is that all conflicts can and should be resolved by using a generic systematic process oriented towards 
persuading parties out of their conflict situation and into a win-win scenario-that is, an agreement or compromise that produces mutual gains (Friedland, 2001).

Scimecca argues further that Roger Fisher and Uri's approach not only overemphasizes rationalchoice as the only explanation, but its assumption of an essential social vacant fails to consider the role culture, social structure, and power play in conflicts: 'The assumption is that rational individuals should be able to resolve their conflicts, and if they cannot, then the problem lies with them" (Scimecca 1993, 213 217).

The desire to create simple models that routinize the analysis and resolution of conflict is an increasingly disturbing trend. The game theory, rational actor, and process approaches are some of the most problematic in the field. They are based completely on assuming rationality (and rationality in a Western sense). Roger Fisher clearly presents himself as being above the conflict, an imperial academic imparting his knowledge on the conflicting parties-speaking to them about how to resolve their conflict rationally. The conflict actors inadvertently are dehumanized in his formula as faceless party A is negotiating with faceless party $\mathrm{B}$, and denied human and intellectual agency, particularly with regard to having input into the conflict resolution process.

Roger Fisher, as an outsider, prescribes generic formulas for resolving all conflicts, an approach that trivializes the complexity of conflict, removing cultural, historical, and other contextual specificities. He fails to consider the role of power disparity in the process of conflict resolution in any significant way and, as such, his approach tends to align with dominant interests. Many other theorists have come to address some of these shortcomings and to advance alternative approaches.

In this sense it can provide more agency to the conflict actors and, further, the interactivity allows for more of a dialectic understanding of conflict. However, it often falls into some serious problems, as it simultaneously has a tendency to downplay power inequality and the unequal distribution of resourcesdiminishing those dynamics down to mere 'perception.' Kelman argues for $\bullet$ non adversarial approaches to conflict resolution, such as interactive problem solving" $(1997,198)$. He proposes problem• solving workshops that should be "governed by a no-fault principle, which eschews efforts to establish who is right and who is wrong from a legal or moral standpoint"(Kelman, 2005).

This becomes problematic particularly when dealing with international conflict that takes place within structures of power inequality. This is especially so in the context of colonialism such as the conflicts in Palestine/Israel and the North of Ireland.

This is a problem, first of all, because he does not seriously consider the U.S. government's central role as an antagonist in the Israeli-Palestinian conflict. Secondly, he straitjackets these conflicts into 'two sides,' not giving adequate attention to the many diverse aspirations, social locations, and identities within those two sides.

Kelman explains that a good example of his conflict resolution model-including mutual recognition and cross community dialogue that result in an agreement-would be "the September 1993 Olso Accords, which helped create the breakthrough in Israeli• Palestinian negotiations" (1997, 206). Another perceptional theorist, Ron Fisher, is a strong supporter of Kelman's technique and conflict analysis. He states that, $\bullet$ The breakthrough of the Norwegian-sponsored back-channel talks of 1993 affirmed many of the principles that Kelman saw as essential for progress in negotiations" (Ron Fisher 1997, 248). He states further that Kelman's workshops "helped build a network of influential who have contributed to a constructive political dialogue and to the emerging conditions for peace in the Middle East" (Ibid). 
Kelman and Fisher emphasize the fact that they are academics, clearly identifying as part of the IPCR 'community.' In contrast to the conflicting parties, they remain 'above' the conflict They stress the importance of dialogue and interactive approaches to conflict resolution. often supporting workshops with 'no-fault' principles. Interactive, social-psychological approaches to dealing with the conflicting parties' 'perceptions' can help give agency to the conflict actors. They also can provide a more dialectic understanding of conflict. They tend to be less prescriptive, providing some subjectivity in allowing conflict actors to frame the situation-to validate their 'perceptions' which are based on their lived experiences. However, these approaches, similar to the liberal multicultural approaches and race-relations management initiatives, fail to address power inequality in any significant way(Ibid).

Moving away from the social psychological approaches are the human needs theorists, most notably John Burton. While Burton does consider the study of conflict resolution to be a study of human behavior and relationships, he argues for a more holistic approach, wherein the entirety of the human, person and social, is studied. Burton is well known for his outspoken challenges to the dominant international relations paradigm of power-politics associated with deterrence theory and a world of mutually assured destruction (Avruch 223). Burton sees the satisfaction of human needs as the primary motivation for human behavior, and the blocking of those needs as the main source of conflict.

Burton stands above the conflict and looks for rational value-free solutions within a generic theoretical frame. He proposes a mechanical connection between deprivation of needs and resistance or deviance. But this is not a mechanical relationship. For example, if there is a famine and people are starving, they often do not have the energy to resist and cause conflict or even to operate outside the legal norms of society in many instances.

Scimecca has criticized the human needs approach further for its emphasis on biology and genetic determinism and for not adequately taking into account the role of social institutions or power disparity.

While Burton has taken some of these critiques into account and has expanded his work a bit in the cultural realm, the human needs approach remains rigidly prescriptive in determining the primary issues in the conflict, giving very little agency to the actual conflict actors. Burton as the scholar-practitioner defines the most important conflict dynamics for the conflict actors. As an outsider, he speaks to them, imposing his analytical frame on their lived experiences, prescribing a formula for the resolution of their conflict The refusal to interrogate power as a central element of conflict analysis can also function to align Burton's approach with dominant interests (Badawi \& Makdisi, 2007).

Other conflict resolution theorists take issue with the neglect of power disparity and challenge the mainstream 'neutrality' approaches, believing that sometimes they can compromise human rights. Johan Galtung uses a "structural violence" approach, explaining that: "the general formula behind structural violence is inequality, above all the distribution of power" $(1969,119)$. Galtung argues that the word 'peace' is used and abused, that it can be on anybody's agenda, and that we must strive for a richer concept of 'peace.' But he also clings to some traditional notions. Galtung asserts "the statement peace as the absence of violence shall be retained". Within this conventional parameter, he attempts to make his contribution by redefining 'violence' in hopes that "an extended concept of violence will lead to an extended concept of peace" $(1969,130)$.

Like the rational-choice theorists and the human needs theorists, the structural violence theorists advocate a 'prescriptive' approach to conflict resolution, which is based on transferring conflict resolution technology from one setting to another".They stand above cultural-historical nuances, and lived conflict experience. Paulo Friere argues that "prescription represents the imposition of one individual's choice upon 
another, transforming the consciousness of the person prescribed to into one that conforms with the prescriber's consciousness" $(1999,29)$.

These approaches presume the moral superiority of the models put forth by the academic practitioners, in contrast to the inferiority of the way in which the actual actors might define the conflict dynamics.

In contrast to the prescriptive approach, Lederach argues for an 'elective' approach "based on building from cultural resources in a given setting". He argues that "understanding conflict and developing appropriate models of handling it will necessarily be rooted in, and must respect and draw from, the culture knowledge of a people". Lederach makes a significant contribution here and this notion of valuing the local culture and the resources of local people in understanding and moving to resolve the conflict is a vital divergence from the prescriptive elements in this field (Lederhandler, 1989).

In addition, it is important to note that some of the feminist literature in this field falls into some of the same dominant trends as the rest of the field. The tendencies to deny agency to nonlife women, to make claims for all women, and to prescribe generic formulas for 'women's liberation' are quite pervasive. Similar to the critiques made of the other approaches, feminist approaches in IPCR often have failed to take cultural nuances and other context specifics into account as such, some of these approaches also have been used to forward notions of western cultural (and academic) superiority. For example, During the UN decade for women, 1975-85, many western feminists increasingly became interested in Arab, Muslim and African 'women's issues,' as they saw them. Under the guise of what was largely a synthetic claim to 'universal sisterhood,' they proceeded to tell Middle Eastern and African women that clitoridectomy and the veil were the pivotal 'women's issues' in their countries.

Furthermore, some of this literature denies agency to women and men who choose to take up arms as part of a liberation struggle. Much of the literature on gender in IPCR. even more so than in the larger IPCR field, is often rigidly committed to nonviolence, frequently viewing all aggression and violence as inherently masculinist and patriarchal (even in insurgent movements). Liz Kelly argues, for example, that "the use of violence-interpersonal, state-sanctioned and insurgent-remains a primarily masculine preserve, and women who enter these terrains do so within a set of long- tanding gendered meanings" $(2000,46)$.

Further. this can reinforce the dominant stereotypes of men in the low power group as being 'prone to violence.' Such notions can buy into traditional racial and colonial constructions that historically have represented men from low power groups as criminals, savages, terrorists, and all usually being misogynist as well.

Kelly views all violence, including insurgency, as inherently anti-feminist. She argues that "oppositional radical/left insurgent movements also draw upon and rework the masculinist values which underpin the structures they are challenging",These types of arguments can have the effect of deflecting attention away from both state repression and women's responses to violence.

Many of these'feminist' absolute-nonviolence critiques of male and female insurgents come from privileged social locations and exclude two important concepts: First, they deny critical agency to female insurgents. For many women in low power groups, their national liberation struggle may be as, if not more, important for them as women's liberation. Their connection to their people (including men) and to their land, often in opposition to a colonial or other dominant power group, can be an integral part of their personal and their feminist identity, which may lead them to take up arms.

\section{Conclusion}


Scholars working in the areas of peace and conflict studies have made significant contributions to the policies used by non-governmental organizations, development agencies, international financial institutions, and the UN system, in the specific areas of conflict resolution and citizen diplomacy, development, political, social, and economic reform, peacekeeping, mediation, early warning, prevention, peacebuilding, and state building.

This represented a shift in interest from conflict management approaches oriented towards a "negative peace" to conflict resolution and peacebuilding approaches aimed at a "positive peace". This emerged rapidly at the end of the Cold War, and was encapsulated in the report of then-UN SecretaryGeneral Boutros Boutros-Ghali, An Agenda for Peace.

Indeed, it might be said that much of the machinery of what has been called "liberal peacebuilding" by a number of scholars and "state building" by another is based largely on the work that has been carried out in this area. Many scholars in the area have advocated a more "emancipatory" form of peacebuilding, however, based upon a "Responsibility to Protect" human security, local ownership and participation in such processes, especially after the limited success of liberal peacebuilding/ state building in places as diverse as Cambodia, the Balkans, East Timor, Sierra Leone, Liberia, Nepal, Afghanistan, and Iraq.

This research agenda is in the process of establishing a more nuanced agenda for peacebuilding which also connects with the original, qualitatively and normatively oriented work that emerged in the peace studies and conflict research schools of the 1960s (e.g. see the Oslo Peace Research Institute research project on "Liberal Peace and the Ethics of Peacebuilding" and the "Liberal Peace Transitions" project at the University of St Andrews) and more critical ideas about peacebuilding that have recently developed in many European and non-western academic and policy circles. Some scholars have pointed towards the hybrid outcomes that have arisen in practice, indicating both the potential and problems of hybrid forms of peace, with an everyday orientation, and suggestive of the emergence of a post-liberal framework.

The UNESCO Chair for Peace Studies at the University of Innsbruck/Austria proposed in 2008 a culture-based classification of peace interpretations: energetic, moral, modern, post-modern and transrational approaches. The trans-rational approach unites existing spiritual interpretations of society and relation with the mechanistic methods of modern peace. Hence this school prefers the strictly relational and systemic method of elective conflict transformation (Lederach) to the prescriptive approaches of modern conflict resolution.

All of the mainstream theoretical approaches reviewed here-game theory, rational choice and process approaches, perceptional and social psychological approaches, human needs approaches, structural violence approaches, and many of the mainstream feminist approaches to IPCR-have been developed by elite-educated scholars and practitioners who strongly identify as part of the 'IPCR community' or some variation thereof. This community is framed largely in contrast to the conflict actors, and tends towards a superiority/inferiority divide along those lines. This creates a process of'othering' in which conflict actors are cast out as 'partisan' or are at least given different hierarchical status from the conflict resolution theorists and practitioners who claim to remain detached and above the conflict.

Taken together, the shortcomings in these approaches demonstrate the four primary deracializing trends in the IPCR field on which I have chosen to focus. The tendency to create a power hierarchy between conflict actors and conflict resolution theorists/practitioners. The tendency to objectify the conflict actors and speak to them, denying them human and intellectual agency. It is also demonstrated the tendency to prescribe generic formulas as an outsider to resolve someone else's conflict, which usually ends up trivializing its complexity and not taking into account the local culture and context. 


\section{References}

Aron, Raymond, Peace and War: A Theory of International Relations, London: Transaction, 2003.

Avruch, Kevin, Peter W. Black, and Joseph A. Scimecca (eds.), Conflict Resolution: Cross-Cultural Perspectives, London: Greenwood Press, 1991.

Azar, Edward E., The Management of Protracted Social Conflict, Hampshire, UK: Dartmouth Publishing, 1990.

Beer, Francis A., Meanings of War and Peace, College Station: Texas A\&M University Press 2001.

Beer, Francis A., Peace Against War, San Francisco: W.H. Freeman, 1981.

Boutros Ghali, An Agenda for Peace: preventative diplomacy, peacemaking and peacekeeping, New York: United Nations, 1992.

Bawer, Bruce "The Peace Racket", City Journal, Summer 2007 link.

Burton, J., \& EA Azar, International Conflict Resolution: Theory and Practice, Wheatsheaf Books, 1986.

Badawi, I. El, \& Makdisi, S. (2007). Explaining the democracy deficit in the Arab world. The Quarterly Review of Economics and Finance, 46(5), 813-831. https://doi.org/10.1016/j.qref.2006.08.009

Friedland, R. (2001). Religious Nationalism and the Problem of Collective Representation. Annual Review of Sociology, 27(1), 125-152. https://doi.org/10.1146/annurev.soc.27.1.125

Gurr, T. D. (1993). Minorities at Risk: A Global View of Ethnopolitical Conflicts. Washington, D.C: Institute of Peace.

Hunt, C. and L. H. (1980). Sociology (Fifth Edit). New York: McGraw-Hill.

Jones, C. (1999). Ideo-theology and the Jewish state: from conflict to conciliation? British Journal of Middle Eastern Studies, 26(1), 9-26. https://doi.org/10.1080/13530199908705675

Kelman, H. (2005). Interactive problem solving: Changing political culture in the pursuit of conflict resolution. Journal of Peace Psychology, 16(4), 389-413.

Kemp, A. (2000). Dramatizing sovereignty: the construction of territorial dispute in the Israeli - Egyptian border at Taba. 19(March 1979), 315-344.

Lasensky, S. (2004). Paying for Peace: The Oslo Process and the Limits of American Foreign Aid. Middle East Journal, 58, 210-234. https://doi.org/papers2://publication/uuid/60ECF944-F2EE-45CF8A8D-940E64B1E550

Lederhandler, E. (1989). The Road to Modern Jewish Politics: Political Tradition and Political Reconstruction in the Jewish Community of Tsarist Russia. New York: Oxford University Press.

Mock, S., Obeidi, A., \& Zeleznikow, J. (2012). A Brief Outline of the Israel-Palestinian Conflict. Group Decision and Negotiation, (April 2012), 1-18. https://doi.org/10.1007/s10726-012-9293-7

Rowe, N. (2011). Dance and Political Credibility: The Appropriation of $<\mathrm{I}>$ Dabkeh $</ \mathrm{I}>$ by Zionism, PanArabism, and Palestinian Nationalism Nicholas Rowe. The Middle East Journal, 65(3), 363-380. https://doi.org/10.3751/65.3.11 
Taylor, Paul, and A. J. R. Groom (eds.), The UN at the Millennium, London: Continuum, 2000.

Tidwell, Alan C., Conflict Resolved, London: Pinter, 1998.

Vayrynen, R, New Directions in Conflict Theory: Conflict Resolution and Conflict Transformation, London: Sage, 1991.

Vedby Rasmussen, Mikkel, The West, Civil Society, and the Construction of Peace, London: Palgrave, 2003.

Wallensteen, Peter (ed.), Peace Research: Achievements and Challenges, Boulder, CO: Westview Press, 1988.

Zartman, William, and Lewis Rasmussen (eds.), Peacemaking in International Conflict: Methods and Techniques, Washington, DC: United States Institute of Peace Press, 1997.

\section{Copyrights}

Copyright for this article is retained by the author(s), with first publication rights granted to the journal.

This is an open-access article distributed under the terms and conditions of the Creative Commons Attribution license (http://creativecommons.org/licenses/by/4.0/). 